\title{
BMJ Open The effect of maternal age and planned place of birth on intrapartum outcomes in healthy women with straightforward pregnancies: secondary analysis of the Birthplace national prospective cohort study
}

\author{
Yangmei Li, ${ }^{1}$ John Townend, ${ }^{1}$ Rachel Rowe, ${ }^{1}$ Marian Knight, ${ }^{1}$ Peter Brocklehurst, ${ }^{2}$ \\ Jennifer Hollowell ${ }^{1}$
}

To cite: Li Y, Townend J, Rowe $\mathrm{R}$, et al. The effect of maternal age and planned place of birth on intrapartum outcomes in healthy women with straightforward pregnancies: secondary analysis of the Birthplace national prospective cohort study. BMJ Open 2014;4: e004026. doi:10.1136/ bmjopen-2013-004026

- Prepublication history and additional material for this paper is available online. To view these files please visit the journal online (http://dx.doi.org/10.1136/ bmjopen-2013-004026).

Received 13 September 2013 Revised 12 December 2013 Accepted 13 December 2013

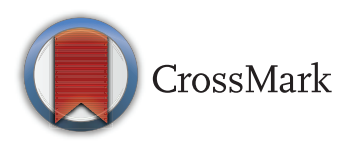

For numbered affiliations see end of article.

\section{Correspondence to} Dr Jennifer Hollowell; jennifer.hollowell@npeu.ox. ac.uk

\section{ABSTRACT}

Objectives: To describe the relationship between maternal age and intrapartum outcomes in 'low-risk' women; and to evaluate whether the relationship between maternal age and intrapartum interventions and adverse outcomes differs by planned place of birth.

Design: Prospective cohort study.

Setting: Obstetric units (OUs), midwifery units and planned home births in England.

Participants: 63371 women aged over 16 without known medical or obstetric risk factors, with singleton pregnancies, planning vaginal birth.

Methods: Log Poisson regression was used to evaluate the association between maternal age, modelled as a continuous and categorical variable, and risk of intrapartum interventions and adverse maternal and perinatal outcomes.

Main outcome measures: Intrapartum caesarean section, instrumental delivery, syntocinon augmentation and a composite measure of maternal interventions/ adverse outcomes requiring obstetric care encompassing augmentation, instrumental delivery, intrapartum caesarean section, general anaesthesia, blood transfusion, third-degree/fourth-degree tear, maternal admission; adverse perinatal outcome (encompassing neonatal unit admission or perinatal death).

Results: Interventions and adverse maternal outcomes requiring obstetric care generally increased with age, particularly in nulliparous women. For nulliparous women aged 16-40, the risk of experiencing an intervention or adverse outcome requiring obstetric care increased more steeply with age in planned non-OU births than in planned OU births (adjusted RR 1.21 per 5-year increase in age, $95 \% \mathrm{Cl} 1.18$ to 1.25 vs adjusted RR $1.12,95 \% \mathrm{Cl} 1.10$ to 1.15$)$ but absolute risks were lower in planned non-OU births at all ages. The risk of neonatal unit admission or perinatal death was significantly raised in nulliparous women aged $40+$ relative to women aged 25-29 (adjusted RR 2.29, 95\% Cl 1.28 to 4.09 ).

\section{Strengths and limitations of this study}

- The study was based on a large, nationally representative cohort of 'low-risk' women, with highquality data collected prospectively.

- The number of women aged over 40 was relatively small, so the study had limited power to explore effects in women over 40, particularly in non-obstetric unit settings.

- Planned births in non-obstetric unit settings were combined; graphical plots indicated that this was reasonable but important differences between settings cannot be ruled out.

Conclusions: At all ages, 'low-risk' women who plan birth in a non-OU setting tend to experience lower intervention rates than comparable women who plan birth in an OU. Younger nulliparous women appear to benefit more from this reduction than older nulliparous women.

\section{BACKGROUND}

The proportion of births in women aged 35 and over has been steadily rising in recent years in the UK and elsewhere. ${ }^{1}$ Currently, approximately $16 \%$ of births in England and Wales are to women aged 35-39 and 4\% of births are to women aged 40 and over. ${ }^{1}$

Advanced maternal age is associated with an increased risk of pregnancy complications including gestational diabetes, ${ }^{3}$ pregnancyinduced hypertension and pre-eclampsia, 45 twin or higher order pregnancies, ${ }^{3}$ breech presentation, ${ }^{6}$ placenta praevia, ${ }^{3}$ 7-9 preterm birth, ${ }^{5}$ post-term birth, ${ }^{11}$ severe maternal morbidity ${ }^{12}$ and adverse perinatal outcomes 
including antepartum stillbirth, ${ }^{13}$ intrapartum-related perinatal death, ${ }^{14}$ early neonatal death ${ }^{15}$ and neonatal unit admission. ${ }^{5}$ Older women also have an increased risk of interventions such as induction and caesarean section. ${ }^{16-20}$ However, many age-related pregnancy complications are known risk factors for intrapartum complications or adverse perinatal outcomes and women with these risk factors would normally be advised to give birth in an obstetric unit (OU). Relatively little is known about the incidence of intrapartum interventions and adverse maternal and perinatal outcomes in older women who do not have known risk factors. ${ }^{21}$

The current clinical guideline in England ${ }^{22}$ recommends that healthy women with straightforward pregnancies should be offered a choice of planned birth at home, in a midwife-led unit or in an OU, but also suggests individual assessment when planning place of birth for women over 40 at booking. ${ }^{22}$ The evidence for 'low-risk' women in general shows that planned birth in a non-OU setting is associated with a lower incidence of intrapartum interventions ${ }^{22-28}$ and research has demonstrated that in 'low-risk' women, after adjustment for maternal characteristics, planned birth in a midwifery unit and planned birth at home (multiparous women only) are not associated with an increased risk to the baby compared with planned birth in an OU. ${ }^{25}$ However, rates of intrapartum transfer increase with age in nulliparous women ${ }^{29}$ and, more generally, the risks that might affect the choice of planned place of birth (PPOB) by healthy older women are not well documented.

The aim of this study was to evaluate the association between maternal age and intrapartum interventions and adverse maternal and perinatal outcomes that may influence the choice of PPOB, in 'low-risk' women with singleton, term pregnancies planning a vaginal birth.

The main objectives were to describe the relationship between maternal age and intrapartum interventions and adverse outcomes that indicate a need for obstetric or neonatal care in 'low-risk' women; and to evaluate whether the relationship between maternal age and intrapartum interventions and adverse outcomes differs by PPOB.

\section{METHODS}

\section{Settings and participants}

The study used data from the Birthplace in England national prospective cohort study which was designed to compare perinatal and maternal outcomes and interventions by PPOB at the start of care in labour.

The cohort study methods are described in full elsewhere. ${ }^{25} 26$ Briefly, the Birthplace cohort included a total of 79774 births between April 2008 and April 2010, including 32257 planned OU births from a stratified random sample of 36 OUs, 11666 planned births in 53 freestanding midwifery units (FMUs), 17582 planned births in 43 alongside midwifery units (AMUs) and
18269 planned home births from 142 National Health Service (NHS) trusts across England. Births were eligible for inclusion if the woman was planning a vaginal birth and received some labour care from an NHS midwife in her planned birth setting. Women who had an elective caesarean section or caesarean section before the onset of labour, presented in preterm labour ( $<37$ weeks' gestation), had a multiple pregnancy, an unplanned home birth or who were 'unbooked' (received no antenatal care) were excluded. Stillbirths occurring before the start of care in labour were excluded. Women in the cohort were classified as 'low-risk' if before the start of labour they were not known to have any of the medical or obstetric risk factors listed in national guidelines on intrapartum care ${ }^{22}$ as 'indicating increased risk suggesting planned birth in an OU'. The study had a high response rate and low levels of missing data. ${ }^{25} 26$

The study population for the analyses reported here was 'low-risk' women in the Birthplace cohort aged 16 years or over at the time of birth, with a term (gestational age $37^{+0}$ to $42^{+0}$ weeks inclusive) pregnancy and parity less than 6. In the National Institute for Health and Care Excellence (NICE) intrapartum care guideline, individual assessment is recommended when planning place of birth for women with parity of six or more and many midwifery units restrict admission to women of parity five or less. ${ }^{30}$ We additionally excluded women for whom age, parity or gestational age was not known.

\section{Data}

As described elsewhere, ${ }^{25}$ maternal characteristics and medical or obstetric risk factors known prior to the onset of labour were extracted from the woman's medical records by the midwife attending the birth. Complicating conditions identified by the midwife at the start of care in labour (eg, prolonged rupture of membranes), intrapartum interventions and adverse maternal and perinatal outcomes were recorded by the attending midwife using a data collection form started during labour and completed on or after the fifth postnatal day.

PPOB (OU, AMU, FMU or home) was based on the intended place of birth at the start of care in labour. Women were included in the group in which they planned to give birth at the start of care in labour regardless of whether they were transferred during labour care or immediately after the birth.

\section{Outcomes}

We focused on outcome measures that reflected interventions and adverse outcomes that indicated a need for obstetric and/or neonatal care, that is, outcomes that would require the woman and/or baby to be transferred to an obstetric or neonatal unit if labour care or birth took place elsewhere. For women, we considered the following outcomes separately and as a combined maternal composite outcome ('interventions/adverse outcomes requiring obstetric care'): augmentation with syntocinon, instrumental delivery (ventouse or forceps), intrapartum 
caesarean section, general anaesthesia, maternal blood transfusion, third-degree/fourth-degree perineal tear and maternal admission for higher level care. The use of epidural/spinal analgesia was also considered as a secondary outcome. The main outcomes considered for women were the maternal composite outcome ('interventions and adverse outcomes requiring obstetric care'), augmentation, instrumental delivery and intrapartum caesarean section.

For babies, we considered a single composite outcome measure largely reflecting admission to a neonatal unit. This 'perinatal composite outcome' encompassed one or more of the following events: admission to a neonatal unit within $48 \mathrm{~h}$ of birth, stillbirth after the onset of labour or early neonatal death.

\section{Statistical analysis}

Analyses were conducted separately by parity. We modelled age at the time of delivery as a categorical and continuous variable, using $\log$ Poisson regression to estimate relative risks adjusted for the following potential confounders: ethnic group, understanding of English, marital or partner status, body mass index (BMI), index of multiple deprivation (IMD) score, gestational age at birth and, where appropriate, PPOB (see online supplementary table S1 for categorisation). We also carried out sensitivity analyses in which we additionally adjusted for the presence of complicating conditions identified at the start of care in labour (none, 1 or more) and for the use of epidural/spinal analgesia.

We fitted a series of models following a prespecified, iterative strategy. In order to test our modelling assumptions regarding age and to determine whether it was appropriate to combine data for planned births in non-OU settings, we plotted outcomes by age and PPOB using polynomial smoothing. ${ }^{31}$ Visual inspection of these plots (see figures 1 and 2 for the main outcomes) indicated that it was reasonable to model age as a continuous variable within the age range 16-40 (inclusive) and further indicated that event rates were generally similar in the three non-OU settings, suggesting that it was reasonable to combine the non-OU settings for the purposes of exploring interactions between maternal age and PPOB. We did not model age as a continuous variable above the age of 40 because data were sparse, particularly for planned non-OU births to nulliparous women, and we could not be confident that the broadly linear trends seen at younger ages could be extrapolated above this age.

We initially modelled the effect of age on study outcomes separately by parity and for all planned places of birth combined. Models in which age was modelled as a continuous variable were restricted to the age range 16-40 inclusive. For each of the study outcomes, we tested for an interaction between age (as a continuous variable) and PPOB (OU vs non-OU) using a Wald test, and where the interaction was significant at the $5 \%$ level, we modelled the effect of age on the outcome separately by PPOB. For outcomes where the interaction between age and PPOB was significant, we calculated crude and adjusted relative risks associated with planned non-OU birth separately for each age band.

In order to test whether the presence of complicating conditions at the start of care in labour (eg,prolonged rupture of membranes) had an effect on the observed relationships, we fitted a further set of models in which we adjusted for maternal characteristics and the presence of complicating conditions. As previous analyses have shown that women planning birth in an OU have a higher prevalence of complicating conditions than in other settings ${ }^{25}$ and this affects the magnitude of the difference in event rates between settings, we carried out further analyses of the main outcomes restricted to 'low-risk' women without complicating conditions at the start of care in labour.

Robust variance estimation was used to allow for the clustered nature of the data and, as described elsewhere, ${ }^{25}{ }^{26}$ probability weights were incorporated to account for differences in the probability of a woman being selected for inclusion in the study arising from differences in each unit/trust's period of participation and the stratum-specific probabilities of selection of OUs. The weighting is such that, when applied to the pooled data for all four settings, the weighted event rates represent the estimated average event rates for England as a whole.

For each outcome, we calculated the number of events, the number of births, the weighted incidence and 95\% CIs. We assessed statistical significance at the $5 \%$ level.

\section{RESULTS}

\section{Description of the study sample}

From the 79774 women in the Birthplace cohort, we excluded 15553 women who had pre-existing risk factors including 'NICE' medical and obstetric risk factors, ${ }^{22}$ grand multiparity (parity six or over) and postterm pregnancy, 62 women who were aged under 16, 682 women who had missing data on risk factors, parity or gestational age and 106 whose age was missing. The study population consisted of 63371 eligible 'low-risk' women. The proportion (weighted) of women who were ineligible because of pre-existing risk factors increased from $31.9 \%$ in women aged $16-19$ to $46.7 \%$ in women aged 40 and over.

Table 1 describes the characteristics of the sample by age. The percentages shown in the table are weighted so that they provide an estimate of the distribution of maternal characteristics that would apply to eligible 'low-risk' births in England. Older women tended to be white, have a fluent understanding of English, and were more likely than younger women to live in a socioeconomically advantaged area. They were less likely than younger women to be nulliparous and more likely to have had multiple previous pregnancies. Planned home births were more common at older ages (table 1 and see online supplementary tables S2 and S3), particularly in 
(A)

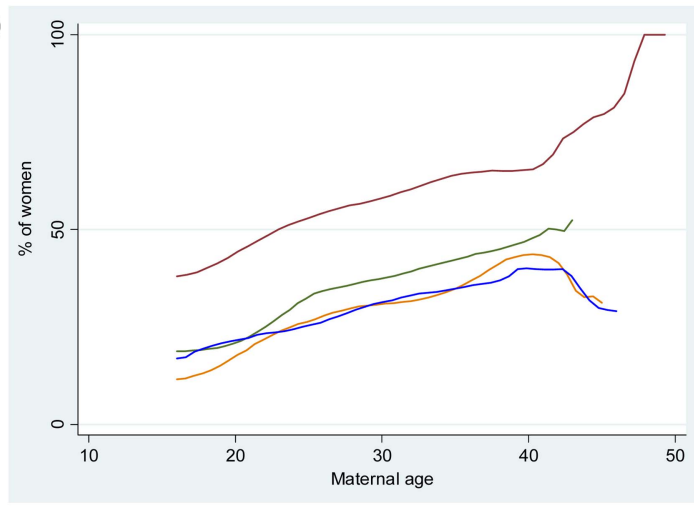

(B)

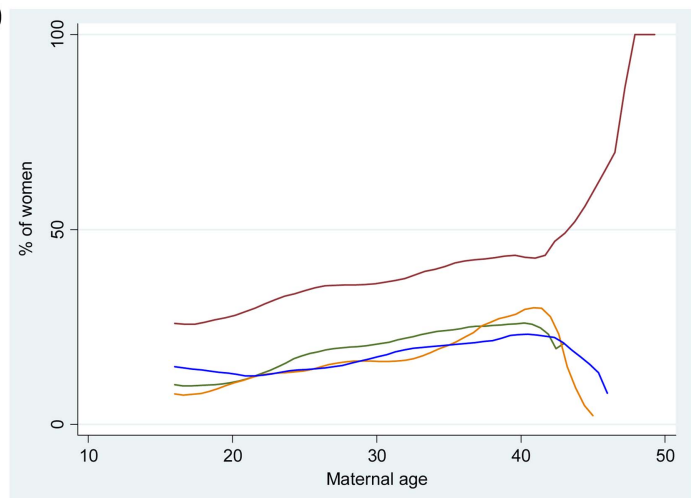

(C)

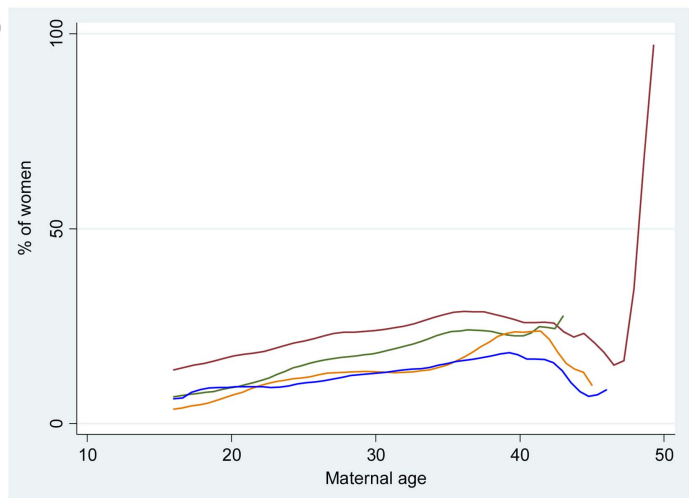

(D)

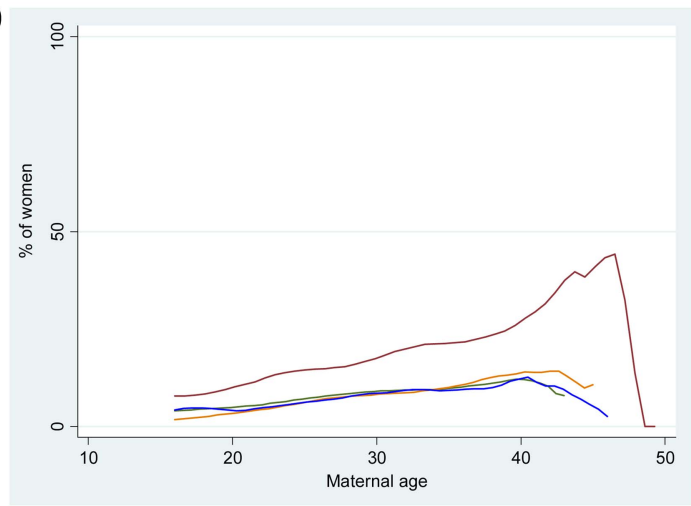

$(\mathrm{E})$

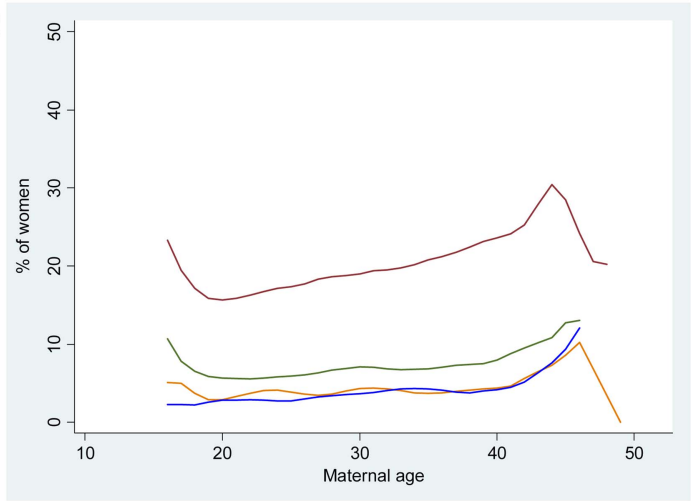

(F)

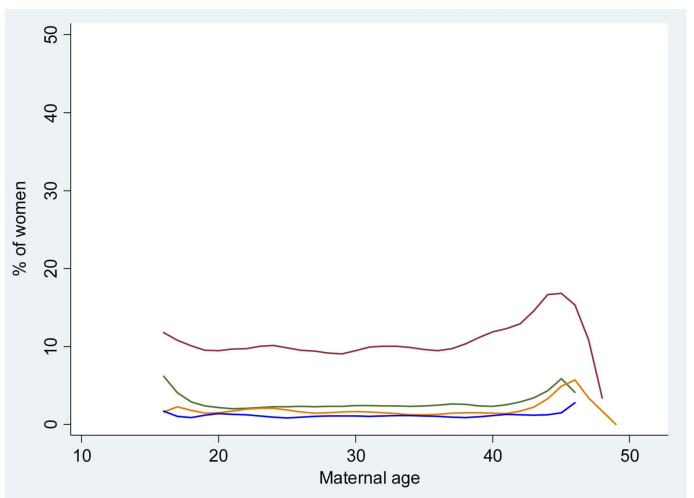

(G)

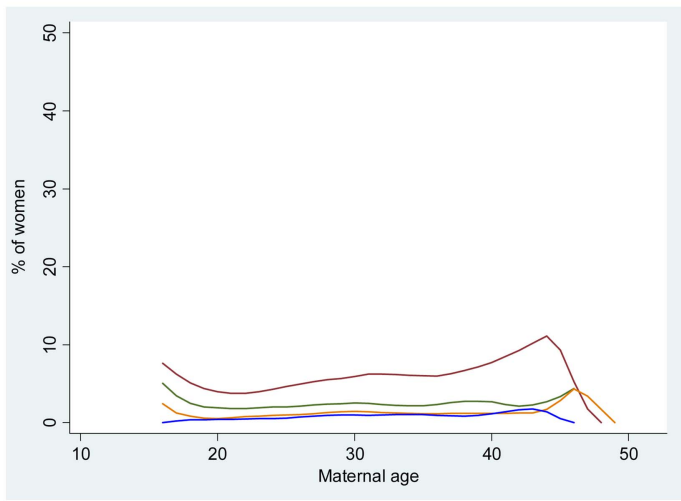

(H)

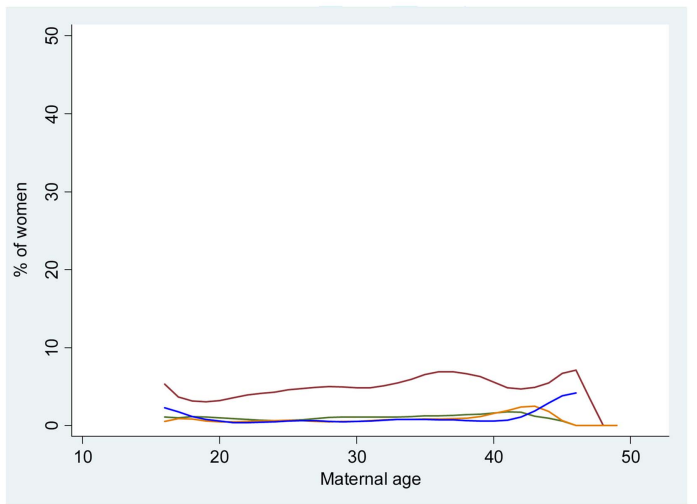

Figure 1 Association between maternal age and intrapartum interventions and adverse maternal outcomes in low-risk women aged 16 and over. NOTE: Graphs are plotted on different scales: 0-100\% for nulliparous women and 0-50\% for multiparous women. (A) Maternal composite, nulliparous women. (B) Augmentation, nulliparous women. (C) Instrumental delivery, nulliparous women. (D) Intrapartum caesarean section, nulliparous women. (E) Maternal composite, multiparous women. (F) Augmentation, multiparous women. (G) Instrumental delivery, multiparous women. $(H)$ Intrapartum caesarean section, multiparous women. 
(A)

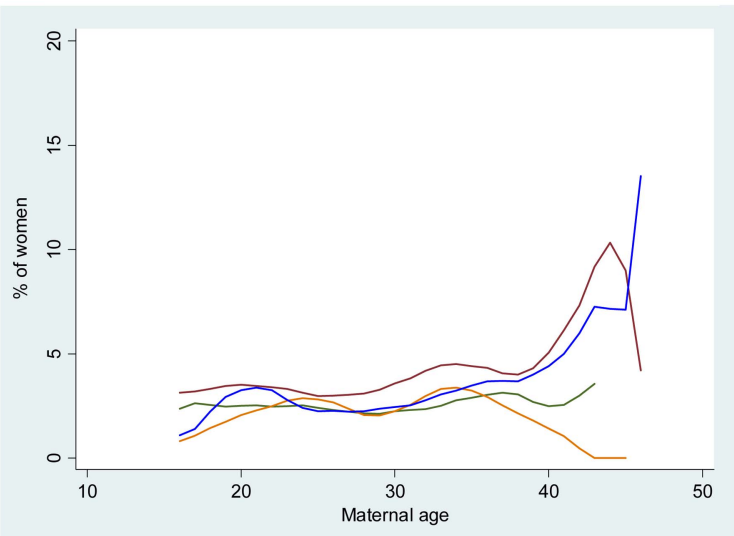

(B)

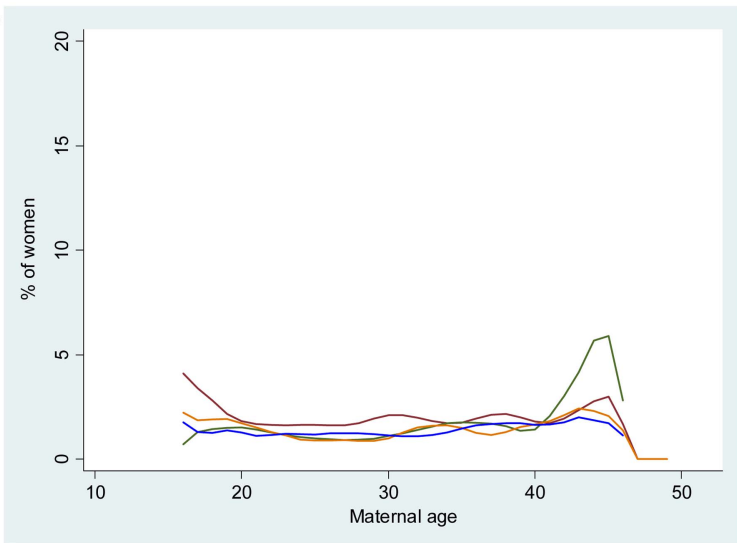

$\longrightarrow$ OU $\longrightarrow$ AMU Home

Figure 2 Association between maternal age and intrapartum interventions and adverse maternal outcomes in low-risk women aged 16 and over. (A) Perinatal composite, nulliparous women. (B) Perinatal composite, multiparous women.

multiparous women (see online supplementary table S3). Older women were more likely to have complicating conditions, such as prolonged rupture of membranes, noted by the midwife at the start of care in labour (table 1). Complicating conditions at start of care in labour were more common in nulliparous women (see online supplementary tables S2 and S3).

\section{Maternal interventions and adverse outcomes}

Descriptive plots of outcomes by age indicated that the incidence of most outcomes tended to increase steadily with age in the age range 16-40, and that incidence rates were generally lower in planned non-OU births (figure 1 and see online supplementary figure S1). Rates for planned OU and non-OU births tended to diverge above this age range, but rates were based on a small number of older women (see online supplementary table S4) particularly for planned AMU and FMU births, and therefore these rates have wide CIs.

For nulliparous women in the age range 16-40 (all PPOBs combined), the adjusted risk of having an intervention/adverse outcome requiring obstetric care (maternal composite) increased significantly with age, as did the risk of augmentation with syntocinon, instrumental delivery, intrapartum caesarean section, thirddegree /fourth-degree perineal tear, or maternal admission for a higher level care (table 2). For augmentation with syntocinon and the maternal composite outcome, the effect of age differed by PPOB (table 2). The risk of augmentation increased more steeply with age in non-OU settings (RR 1.23, 95\% CI 1.18 to 1.28 for every 5 -year increase in age in planned non-OU births vs 1.12 , $95 \%$ CI 1.07 to 1.17 for planned OU births). Nevertheless, the proportion of women receiving augmentation was lower in planned non-OU births at all ages (table 3). For example, $42.2 \%$ (95\% CI $36.4 \%$ to $48.1 \%$ ) of nulliparous women aged 35-39 who planned birth in an $\mathrm{OU}$ received augmentation with syntocinon compared with $22.6 \%$ (95\% CI $19.8 \%$ to $25.7 \%$ ) of nulliparous women of the same age who planned birth in a non-OU setting. A similar pattern was observed for the maternal composite outcome: the risk of an intervention/adverse outcome requiring obstetric care (maternal composite) increased slightly more steeply with age in the non-OU settings (RR 1.21, 95\% CI 1.18 to 1.25 for every 5 -year increase in age in planned non-OU births vs $1.12,95 \%$ CI 1.10 to 1.15 for planned OU births) but the absolute risk was lower in the planned non-OU birth at all ages (table 3). For example, $65.5 \%$ (95\% CI $61.8 \%$ to $69.1 \%$ ) of nulliparous women aged 35-39 who planned birth in an OU experienced an intervention/adverse outcome requiring obstetric care compared with $39.9 \%$ (95\% CI $36.0 \%$ to $43.9 \%$ ) of nulliparous women of the same age who planned birth in a non-OU setting. In nulliparous women, the risk of instrumental delivery and intrapartum caesarean section increased significantly with age (RR 1.18, 95\% CI 1.12 to 1.25 and RR 1.27, 95\% CI 1.23 to 1.32 ) across all settings. Again, absolute risks were substantially lower in planned non-OU births (table 3).

Similar patterns were observed when we adjusted for complicating conditions at the start of care in labour in order to take account of difference between settings in complicating conditions at the start of care in labour (23.9\% in nulliparous planned OU births vs $8.6 \%$ in nulliparous planned-non-OU births; see online supplementary table S5).

However, although the risk of intervention increased with age, at all ages, nulliparous women who planned birth in a non-OU setting had a significantly reduced risk of receiving augmentation or of experiencing an intervention/adverse outcome requiring obstetric care. Table 4 shows the adjusted risks by age for the two outcomes (maternal composite and augmentation) where the effect of PPOB differed by age.

For multiparous women aged 16-40 (all PPOBs combined), the combined risk of having an intervention or adverse outcome requiring obstetric care (maternal 
Table 1 Characteristics of low-risk women aged 16 and over by maternal age category

\begin{tabular}{|c|c|c|c|c|c|c|c|c|c|c|c|c|}
\hline & \multirow{2}{*}{\multicolumn{2}{|c|}{$\frac{16-19 \text { years }}{n=3354}$}} & \multirow{2}{*}{\multicolumn{2}{|c|}{$\frac{20-24 \text { years }}{n=11395}$}} & \multirow{2}{*}{\multicolumn{2}{|c|}{$\frac{25-29 \text { years }}{n=18091}$}} & \multirow{2}{*}{\multicolumn{2}{|c|}{$\begin{array}{l}30-34 \text { years } \\
n=18453\end{array}$}} & \multirow{2}{*}{\multicolumn{2}{|c|}{$\frac{35-39 \text { years }}{n=10397}$}} & \multirow{2}{*}{\multicolumn{2}{|c|}{$\frac{\geq 40 \text { years }}{n=1681}$}} \\
\hline & & & & & & & & & & & & \\
\hline & $\overline{\mathbf{n}}$ & Weighted \%* & $\overline{\mathbf{n}}$ & Weighted \%* & $\overline{\mathbf{n}}$ & Weighted \%* & $\bar{n}$ & Weighted \%* & $\bar{n}$ & Weighted \%* & $\overline{\mathbf{n}}$ & Weighted \%* \\
\hline \multicolumn{13}{|l|}{ Ethnic group } \\
\hline White & 3078 & 90.1 & 9685 & 81.2 & 15146 & 77.5 & 16052 & 80.7 & 9339 & 84.3 & 1527 & 86.6 \\
\hline Non-white & 275 & 9.9 & 1697 & 18.8 & 2920 & 22.5 & 2375 & 19.3 & 1044 & 15.8 & 153 & 13.4 \\
\hline Missing & 1 & & 13 & & 25 & & 26 & & 14 & & 1 & \\
\hline \multicolumn{13}{|l|}{ Understanding of English } \\
\hline Fluent & 3254 & 96.7 & 10394 & 89.6 & 16757 & 90.0 & 17605 & 92.9 & 10155 & 96.3 & 1638 & 96.7 \\
\hline Not fluent & 94 & 3.3 & 948 & 10.4 & 1251 & 10.0 & 776 & 7.1 & 214 & 3.7 & 36 & 3.4 \\
\hline Missing & 6 & & 53 & & 83 & & 72 & & 28 & & 7 & \\
\hline \multicolumn{13}{|l|}{ Marital/partner status } \\
\hline Married/living with partner & 1836 & 51.9 & 9550 & 81.8 & 16868 & 92.1 & 17782 & 96.1 & 10004 & 95.4 & 1591 & 94.4 \\
\hline Single/unsupported by partner & 1440 & 48.1 & 1677 & 18.2 & 1010 & 7.9 & 493 & 3.9 & 293 & 4.7 & 68 & 5.7 \\
\hline Missing & 78 & & 168 & & 213 & & 178 & & 100 & & 22 & \\
\hline \multicolumn{13}{|l|}{ BMI in pregnancy $\left(\mathrm{kg} / \mathrm{m}^{2}\right)$} \\
\hline$<18.5$ & 184 & 6.2 & 426 & 4.2 & 413 & 2.6 & 337 & 2.1 & 156 & 1.5 & 18 & 0.2 \\
\hline $18.5-24.9$ & 1753 & 50.3 & 5316 & 45.6 & 8560 & 45.9 & 9059 & 46.7 & 4864 & 44.5 & 802 & 46.4 \\
\hline $25-29.9$ & 598 & 17.9 & 2558 & 21.7 & 4341 & 24.6 & 4206 & 23.2 & 2572 & 26.9 & 415 & 27.6 \\
\hline $30-35$ & 233 & 7.6 & 1096 & 10.0 & 1627 & 9.3 & 1399 & 8.8 & 769 & 8.9 & 109 & 8.1 \\
\hline Not recorded & 581 & 18.1 & 1969 & 18.4 & 3091 & 17.6 & 3389 & 19.2 & 2000 & 18.3 & 329 & 17.7 \\
\hline Missing & 5 & & 30 & & 59 & & 63 & & 36 & & 8 & \\
\hline \multicolumn{13}{|l|}{ IMD quintile } \\
\hline 1st (least deprived) & 245 & 6.8 & 1102 & 8.5 & 2875 & 13.8 & 4255 & 20.5 & 2783 & 24.6 & 434 & 26.0 \\
\hline 2nd & 405 & 12.3 & 1521 & 13.3 & 3259 & 17.5 & 4114 & 21.7 & 2434 & 22.3 & 396 & 22.0 \\
\hline 3rd & 637 & 18.2 & 2115 & 18.0 & 3657 & 18.6 & 3759 & 19.7 & 2135 & 20.0 & 357 & 21.6 \\
\hline 4th & 827 & 25.3 & 2784 & 23.9 & 3957 & 22.7 & 3479 & 19.8 & 1765 & 17.9 & 291 & 16.9 \\
\hline 5th (most deprived) & 1221 & 37.5 & 3821 & 36.2 & 4262 & 27.5 & 2759 & 18.4 & 1215 & 15.2 & 197 & 13.7 \\
\hline Missing & 19 & & 52 & & 81 & & 87 & & 65 & & 6 & \\
\hline \multicolumn{13}{|l|}{ Previous pregnancies $\geq 24$ weeks } \\
\hline 0 & 2835 & 86.8 & 6341 & 62.0 & 8438 & 53.6 & 7307 & 46.7 & 2989 & 36.9 & 346 & 28.0 \\
\hline 1 & 474 & 12.1 & 3772 & 29.4 & 5892 & 29.9 & 6963 & 33.9 & 3929 & 35.5 & 540 & 32.3 \\
\hline 2 & 38 & 0.8 & 1006 & 6.8 & 2549 & 10.9 & 2779 & 12.2 & 2260 & 17.4 & 414 & 20.2 \\
\hline $\begin{array}{l}3-5 \\
\text { Missing }\end{array}$ & 7 & 0.3 & 276 & 1.9 & 1212 & 5.6 & 1404 & 7.2 & 1219 & 10.2 & 381 & 19.5 \\
\hline \multicolumn{13}{|c|}{ Gestation at delivery (completed weeks) } \\
\hline 37 & 119 & 4.1 & 351 & 3.5 & 530 & 3.6 & 534 & 3.5 & 275 & 3.1 & 52 & 3.2 \\
\hline 38 & 305 & 11.0 & 1136 & 10.1 & 1743 & 9.9 & 1739 & 9.9 & 971 & 10.2 & 146 & 9.9 \\
\hline 39 & 783 & 22.5 & 2788 & 24.4 & 4409 & 24.2 & 4439 & 23.5 & 2516 & 23.2 & 410 & 27.2 \\
\hline 40 & 1292 & 36.7 & 4361 & 36.7 & 6970 & 36.2 & 7090 & 37.5 & 3933 & 35.9 & 639 & 35.0 \\
\hline $41-42+0$ days & 855 & 25.7 & 2759 & 25.3 & 4439 & 26.1 & 4651 & 25.6 & 2702 & 27.7 & 434 & 24.7 \\
\hline
\end{tabular}

Continued 


\begin{tabular}{|c|c|c|c|c|c|c|c|c|c|c|c|c|}
\hline & \multirow{2}{*}{\multicolumn{2}{|c|}{$\frac{16-19 \text { years }}{n=3354}$}} & \multirow{2}{*}{\multicolumn{2}{|c|}{$\frac{20-24 \text { years }}{n=11395}$}} & \multirow{2}{*}{\multicolumn{2}{|c|}{$\frac{25-29 \text { years }}{n=18091}$}} & \multirow{2}{*}{\multicolumn{2}{|c|}{$\frac{30-34 \text { years }}{n=18453}$}} & \multirow{2}{*}{\multicolumn{2}{|c|}{$\begin{array}{l}35-39 \text { years } \\
n=10397\end{array}$}} & \multirow{2}{*}{\multicolumn{2}{|c|}{$\frac{\geq 40 \text { years }}{n=1681}$}} \\
\hline & & & & & & & & & & & & \\
\hline & $\bar{n}$ & Weighted \%* & $\bar{n}$ & Weighted \%* & $\bar{n}$ & Weighted \%* & $\bar{n}$ & Weighted \%* & $\mathbf{n}$ & Weighted \%* & $\bar{n}$ & Weighted \%* \\
\hline \multicolumn{13}{|l|}{ Planned place of birth } \\
\hline OU & 1445 & 87.5 & 4150 & 84.9 & 5601 & 82.6 & 4946 & 80.7 & 2571 & 80.2 & 497 & 83.2 \\
\hline AMU & 1038 & 8.5 & 3445 & 9.6 & 4958 & 10.1 & 4540 & 10.3 & 2212 & 9.6 & 294 & 7.9 \\
\hline FMU & 661 & 3.2 & 2115 & 3.5 & 3242 & 3.8 & 3216 & 3.9 & 1674 & 3.8 & 249 & 3.0 \\
\hline Home & 210 & 0.8 & 1685 & 2.0 & 4290 & 3.5 & 5751 & 5.1 & 3940 & 6.4 & 641 & 5.8 \\
\hline \multicolumn{13}{|l|}{ Birth weight (g) } \\
\hline$<2500$ & 53 & 1.9 & 146 & 1.8 & 166 & 1.4 & 159 & 1.1 & 75 & 1.0 & 17 & 1.3 \\
\hline 2500-2999 & 561 & 18.4 & 1728 & 16.4 & 2281 & 14.5 & 1924 & 12.7 & 1100 & 12.5 & 168 & 12.8 \\
\hline $3000-3499$ & 1502 & 44.6 & 4678 & 41.1 & 7171 & 39.3 & 6960 & 38.2 & 3644 & 36.5 & 596 & 37.1 \\
\hline 3500-3999 & 977 & 28.4 & 3664 & 30.9 & 6256 & 33.4 & 6767 & 35.0 & 3888 & 35.3 & 617 & 36.9 \\
\hline $4000-4499$ & 233 & 6.0 & 1023 & 8.7 & 1926 & 10.0 & 2294 & 11.4 & 1432 & 12.5 & 239 & 9.9 \\
\hline$\geq 4500$ & 21 & 0.7 & 135 & 1.2 & 262 & 1.5 & 303 & 1.6 & 237 & 2.3 & 40 & 2.0 \\
\hline Missing & 7 & & 21 & & 29 & & 46 & & 21 & & 4 & \\
\hline \multicolumn{13}{|c|}{ Complicating conditions identified at the start of care in labour } \\
\hline $\begin{array}{l}\text { Prolonged rupture of } \\
\text { membranes }>18 \mathrm{~h}\end{array}$ & 145 & 7.1 & 411 & 6.1 & 678 & 6.5 & 706 & 7.1 & 415 & 7.0 & 78 & 8.9 \\
\hline Meconium stained liquor & 126 & 5.8 & 322 & 4.8 & 469 & 5.0 & 541 & 6.1 & 295 & 5.9 & 60 & 7.4 \\
\hline Proteinuria $1+$ or more & 79 & 2.3 & 203 & 1.7 & 261 & 1.9 & 226 & 1.6 & 109 & 1.7 & 20 & 1.6 \\
\hline Hypertension & 55 & 2.6 & 160 & 2.2 & 232 & 2.4 & 207 & 2.0 & 102 & 2.1 & 17 & 2.0 \\
\hline Abnormal vaginal bleeding & 16 & 0.7 & 57 & 0.9 & 79 & 0.9 & 119 & 1.5 & 77 & 2.1 & 16 & 2.1 \\
\hline Non-cephalic presentation & 5 & 0.2 & 31 & 0.5 & 44 & 0.4 & 64 & 0.5 & 46 & 0.7 & 3 & 0.3 \\
\hline Abnormal fetal heart rate & 41 & 1.5 & 106 & 1.7 & 162 & 1.8 & 143 & 1.7 & 82 & 1.7 & 27 & 3.0 \\
\hline Other complications & 14 & 0.6 & 24 & 0.3 & 23 & 0.2 & 27 & 0.1 & 11 & 0.2 & 2 & 0.2 \\
\hline Any complicating condition & 431 & 18.5 & 1175 & 16.1 & 1744 & 16.6 & 1829 & 18.0 & 1001 & 18.1 & 199 & 22.5 \\
\hline
\end{tabular}

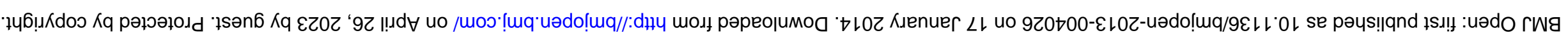


Table 2 Association between maternal age (per 5-year increase) and maternal and perinatal outcomes in low-risk women aged between 16 and 40 years old (inclusive)

\begin{tabular}{|c|c|c|c|c|c|c|c|c|}
\hline & \multicolumn{4}{|c|}{ Nulliparous women } & \multicolumn{4}{|c|}{ Multiparous women } \\
\hline & \multicolumn{2}{|c|}{ Unadjusted $^{\star}$} & \multicolumn{2}{|c|}{ Adjusted*,† } & \multicolumn{2}{|c|}{ Unadjusted $^{\star}$} & \multicolumn{2}{|c|}{ Adjusted $^{\star}, \dagger$} \\
\hline & $\overline{\mathbf{R R}}$ & $(95 \% \mathrm{Cl})$ & $\overline{\mathbf{R R}}$ & $(95 \% \mathrm{Cl})$ & $\overline{\mathbf{R R}}$ & $(95 \% \mathrm{Cl})$ & $\overline{\mathbf{R R}}$ & $(95 \% \mathrm{Cl})$ \\
\hline Maternal composite & 1.13 & (1.11 to 1.16$)$ & 1.13 & (1.11 to 1.16$)$ & 1.07 & (1.03 to 1.13$)$ & 1.08 & (1.03 to 1.14$)$ \\
\hline OU¥ & 1.13 & (1.11 to 1.16$)$ & 1.12 & (1.10 to 1.15$)$ & & & & \\
\hline \multirow{2}{*}{ Non-OU¥ } & 1.22 & (1.19 to 1.26$)$ & 1.21 & (1.18 to 1.25$)$ & & & & \\
\hline & & \multicolumn{2}{|c|}{ Wald test for interaction } & $p<0.001^{\star}, \S$ & & \multicolumn{2}{|c|}{ Wald test for interaction } & $p=0.34^{\star}, \S$ \\
\hline Augmentation & 1.13 & (1.09 to 1.16$)$ & 1.12 & (1.08 to 1.17$)$ & 1.00 & (0.92 to 1.08$)$ & 1.01 & (0.92 to 1.11$)$ \\
\hline OU‡ & 1.13 & (1.09 to 1.17 ) & 1.12 & (1.07 to 1.17$)$ & & & & \\
\hline \multirow{2}{*}{ Non-OU¥ } & 1.25 & (1.20 to 1.31$)$ & 1.23 & (1.18 to 1.28$)$ & & & & \\
\hline & & \multicolumn{2}{|c|}{ Wald test for interaction } & $p<0.001^{*}, \S$ & & \multicolumn{2}{|c|}{ Wald test for interaction } & $p=0.24^{\star}, \S$ \\
\hline \multirow[t]{2}{*}{ Instrumental delivery } & 1.20 & (1.13 to 1.26$)$ & 1.18 & (1.12 to 1.25$)$ & 1.14 & (1.04 to 1.25$)$ & 1.15 & (1.05 to 1.27$)$ \\
\hline & & \multicolumn{2}{|c|}{ Wald test for interaction } & $\mathrm{p}=0.18^{\star}, \S$ & & \multicolumn{2}{|c|}{ Wald test for interaction } & $\mathrm{p}=0.06^{\star}, \S$ \\
\hline \multirow{2}{*}{ Intrapartum caesarean section } & 1.27 & (1.23 to 1.31$)$ & 1.27 & (1.23 to 1.32$)$ & 1.16 & $(1.07$ to 1.26$)$ & 1.16 & (1.06 to 1.28$)$ \\
\hline & & \multicolumn{2}{|c|}{ Wald test for interaction } & $\mathrm{p}=0.26^{\star}, \S$ & & \multicolumn{2}{|c|}{ Wald test for interaction } & $p=0.50^{*}, \S$ \\
\hline \multirow[t]{2}{*}{ General anaesthesia } & 1.06 & (0.93 to 1.20$)$ & 1.06 & (0.92 to 1.22$)$ & 1.05 & (0.87 to 1.27$)$ & 1.09 & (0.91 to 1.32$)$ \\
\hline & & \multicolumn{2}{|c|}{ Wald test for interaction } & $\mathrm{p}=0.83^{*}, \S$ & & \multicolumn{2}{|c|}{ Wald test for interaction } & $\mathrm{p}=0.15^{\star}, \S$ \\
\hline \multirow{2}{*}{ Maternal blood transfusion } & 1.09 & (0.97 to 1.23$)$ & 1.13 & (0.95 to 1.34$)$ & 1.23 & (0.95 to 1.60$)$ & 1.24 & (0.94 to 1.62$)$ \\
\hline & & \multicolumn{2}{|c|}{ Wald test for interaction } & $\mathrm{p}=0.38^{\star}, \S$ & & \multicolumn{2}{|c|}{ Wald test for interaction } & $\mathrm{p}=0.44^{\star}, \S$ \\
\hline \multirow[t]{2}{*}{ Third/fourth degree perineal tear } & 1.17 & (1.09 to 1.27$)$ & 1.12 & (1.02 to 1.23$)$ & 1.10 & (0.98 to 1.23$)$ & 1.01 & (0.89 to 1.15$)$ \\
\hline & & \multicolumn{2}{|c|}{ Wald test for interaction } & $\mathrm{p}=0.43^{\star}, \S$ & & \multicolumn{2}{|c|}{ Wald test for interaction } & $\mathrm{p}=0.29^{\star}, \S$ \\
\hline \multirow{2}{*}{ Maternal admission for higher level care } & 1.28 & (1.03 to 1.58$)$ & 1.46 & (1.07 to 1.99$)$ & 1.40 & (1.01 to 1.92$)$ & 1.49 & (1.06 to 2.10$)$ \\
\hline & & \multicolumn{2}{|c|}{ Wald test for interaction } & $\mathrm{p}=0.41^{*}, \S$ & & \multicolumn{2}{|c|}{ Wald test for interaction } & $\mathrm{p}=0.15^{\star}, \S$ \\
\hline \multirow[t]{2}{*}{ Perinatal composite } & 1.07 & (0.97 to 1.17 ) & 1.06 & (0.95 to 1.17$)$ & 1.02 & (0.87 to 1.19$)$ & 0.98 & (0.84 to 1.15$)$ \\
\hline & & \multicolumn{2}{|c|}{ Wald test for interaction } & $\mathrm{p}=0.92^{*}, \S$ & & Wald test for ir & tion & $\mathrm{p}=0.66^{\star}, \S$ \\
\hline $\begin{array}{l}{ }^{*} \text { Probability weights are incorporated to accou } \\
\text { participation and the stratum-specific probabili } \\
\text { †Adjusted for ethnic group, understanding of } \\
\text { AMU vs FMU vs home). } \\
\text { fResults in these rows were adjusted for ethni } \\
\text { \$p for interaction; results in these rows were a } \\
\text { delivery and planned place of birth (OU vs nor } \\
\text { AMU, alongside midwifery unit; BMI, body ma }\end{array}$ & $\begin{array}{l}\text { marit } \\
\text {, und } \\
\text { for et }\end{array}$ & $\begin{array}{l}\text { the probability of } \\
\text { Us. } \\
\text { er status, BMI in } \\
\text { ling of English, m } \\
\text { oup, understandi } \\
\text { standing midwifer }\end{array}$ & $\begin{array}{l}\text { ncy, in } \\
\text { artner } \\
\text { glish, }\end{array}$ & $\begin{array}{l}\text { ted for inclusio } \\
\text { nultiple depriva } \\
\text { 3Ml in pregnan } \\
\text { partner status, }\end{array}$ & reg & $\begin{array}{l}\text { rom differences } \\
\text { station at delive } \\
\text { eprivation score } \\
\text { lex of multiple }\end{array}$ & $\begin{array}{l}\text { and } \\
\text { on s }\end{array}$ & $\begin{array}{l}\text { eriod of } \\
\text { of birth (OU vs } \\
\mathrm{n} \text { at delivery. } \\
\text { tile, gestation at }\end{array}$ \\
\hline
\end{tabular}


Table 3 Intrapartum interventions and adverse maternal outcomes by maternal age in low-risk nulliparous women aged 16 and over

\begin{tabular}{|c|c|c|c|c|c|c|}
\hline \multirow[b]{3}{*}{ Age (years) } & \multirow{3}{*}{$\begin{array}{l}\text { Events/births } \\
\mathrm{n} / \mathrm{N}\end{array}$} & \multicolumn{2}{|l|}{ OU } & \multirow{3}{*}{$\begin{array}{l}\text { Events/births } \\
\mathrm{n} / \mathrm{N}\end{array}$} & \multirow{2}{*}{\multicolumn{2}{|c|}{$\frac{\text { Non-OU }}{\text { Weighted }^{\star}}$}} \\
\hline & & \multicolumn{2}{|c|}{ Weighted $^{\star}$} & & & \\
\hline & & $\overline{\%}$ & $(95 \% \mathrm{Cl})$ & & $\overline{\%}$ & (95\% Cl) \\
\hline \multicolumn{7}{|c|}{ Maternal composite } \\
\hline $16-19$ & $480 / 1239$ & 39.4 & (35.6 to 43.3 ) & $252 / 1553$ & 17.5 & (15.2 to 20.1$)$ \\
\hline $20-24$ & $1229 / 2577$ & 47.9 & (44.7 to 51.1 ) & $886 / 3679$ & 24.2 & (21.8 to 26.8 ) \\
\hline $25-29$ & $1670 / 3003$ & 55.6 & (53.4 to 57.9 ) & $1680 / 5354$ & 32.3 & (29.5 to 35.2 ) \\
\hline $30-34$ & $1402 / 2322$ & 61.1 & (57.3 to 64.8 ) & $1730 / 4897$ & 36.6 & (34.2 to 39.1 ) \\
\hline $35-39$ & $622 / 957$ & 65.5 & (61.8 to 69.1$)$ & $792 / 1995$ & 39.9 & (36.0 to 43.9 ) \\
\hline $40+$ & $108 / 148$ & 71.9 & (63.0 to 79.3 ) & $83 / 196$ & 44.8 & (35.2 to 54.7 ) \\
\hline Total & $5511 / 10246$ & 54.4 & (51.9 to 56.9 ) & $5423 / 17674$ & 31.3 & (29.3 to 33.4 ) \\
\hline \multicolumn{7}{|c|}{ Augmentation } \\
\hline $16-19$ & $317 / 1245$ & 25.9 & (22.5 to 29.7 ) & $141 / 1564$ & 8.6 & (7.0 to 10.5$)$ \\
\hline $20-24$ & $790 / 2584$ & 30.7 & (26.9 to 34.7 ) & $489 / 3706$ & 12.9 & (11.1 to 14.9$)$ \\
\hline $25-29$ & $1079 / 3011$ & 35.7 & (33.4 to 38.1 ) & $918 / 5372$ & 17.4 & (15.6 to 19.3 ) \\
\hline $30-34$ & $867 / 2318$ & 37.5 & (34.1 to 41.1 ) & $964 / 4921$ & 19.9 & (18.3 to 21.7 ) \\
\hline $35-39$ & $402 / 955$ & 42.2 & (36.4 to 48.1 ) & $473 / 2015$ & 22.6 & (19.8 to 25.7 ) \\
\hline $40+$ & $71 / 149$ & 47.6 & (37.0 to 58.4$)$ & $44 / 196$ & 23.7 & (15.7 to 34.1$)$ \\
\hline Total & $3526 / 10262$ & 34.6 & (31.9 to 37.4 ) & $3029 / 17774$ & 16.9 & (15.7 to 18.1$)$ \\
\hline \multicolumn{7}{|c|}{ Instrumental delivery } \\
\hline $16-19$ & $191 / 1266$ & 15.1 & (12.5 to 18.2$)$ & $99 / 1568$ & 7.9 & (6.2 to 10.2$)$ \\
\hline $20-24$ & $469 / 2618$ & 17.9 & (15.9 to 20.0$)$ & $392 / 3717$ & 10.6 & (8.9 to 12.5$)$ \\
\hline $25-29$ & $707 / 3039$ & 23.4 & (21.3 to 25.6$)$ & $772 / 5391$ & 15.0 & (13.1 to 17.0$)$ \\
\hline $30-34$ & $591 / 2349$ & 26.3 & (21.3 to 32.1 ) & $795 / 4950$ & 17.0 & (15.2 to 19.1$)$ \\
\hline $35-39$ & $275 / 968$ & 29.5 & (25.0 to 34.4 ) & $401 / 2018$ & 19.4 & (15.9 to 23.6 ) \\
\hline $40+$ & $41 / 149$ & 30.4 & (20.0 to 43.2 ) & $37 / 197$ & 21.0 & (13.3 to 31.5$)$ \\
\hline Total & $2274 / 10389$ & 22.5 & (19.9 to 25.3 ) & $2496 / 17841$ & 14.5 & (13.0 to 16.0 ) \\
\hline \multicolumn{7}{|c|}{ Intrapartum caesarean section } \\
\hline $16-19$ & $101 / 1266$ & 8.3 & (6.5 to 10.5$)$ & $55 / 1568$ & 3.3 & (2.5 to 4.2$)$ \\
\hline $20-24$ & $313 / 2618$ & 12.2 & (10.4 to 14.2$)$ & $194 / 3717$ & 5.2 & (4.2 to 6.5$)$ \\
\hline $25-29$ & $461 / 3039$ & 15.2 & (13.3 to 17.2$)$ & $408 / 5391$ & 8.0 & (6.9 to 9.3 ) \\
\hline $30-34$ & $466 / 2349$ & 19.8 & (17.5 to 22.3 ) & $452 / 4950$ & 9.0 & (7.9 to 10.4$)$ \\
\hline $35-39$ & $223 / 968$ & 23.0 & (19.8 to 26.5$)$ & $212 / 2018$ & 11.2 & (9.0 to 13.9 ) \\
\hline $40+$ & $47 / 149$ & 29.2 & (20.9 to 39.3 ) & $22 / 197$ & 9.7 & (5.2 to 17.2 ) \\
\hline Total & $1611 / 10389$ & 15.7 & (14.1 to 17.5$)$ & $1343 / 17841$ & 7.6 & $(6.8$ to 8.4$)$ \\
\hline
\end{tabular}

*Percentages are weighted to take account of differences in the probability of a woman being selected for inclusion in the study arising from differences in each unit/trust's period of participation and the stratum-specific probabilities of selection of OUs.

OU, obstetric unit.

composite) or of instrumental delivery, intrapartum caesarean section and maternal admission for higher level care increased with age (table 2). Augmentation with syntocinon, general anaesthesia, blood transfusion, and third-degree /fourth-degree perineal tear were not associated with maternal age in multiparous women (table 2). For all of the outcomes considered, the effect of age did not differ by PPOB in multiparous women (table 2). Again, for the maternal composite outcome, augmentation with syntocinon, instrumental delivery and intrapartum caesarean section, the absolute event rates were lower in planned non-OU births in most age categories (table 5). For example, $9.8 \%$ (95\% CI $8.2 \%$ to $11.6 \%$ ) of multiparous women aged 35-39 who planned birth in an OU received augmentation with syntocinon compared with $1.8 \%$ (95\% CI $1.3 \%$ to $2.5 \%)$ of women of the same age who planned birth in a non-OU setting.
Up to age 40, other less common outcomes did not increase significantly with maternal age in nulliparous or multiparous women with the exception of maternal admission for higher level care (table 2 and see online supplementary tables S6 and S7).

Absolute event rates for the main outcomes (maternal composite, augmentation with syntocinon, instrumental delivery, intrapartum caesarean section and perinatal composite) were reduced when the analysis was restricted to women without complicating conditions identified at start of labour care (see online supplementary tables S8 and S9). However, at all ages, nulliparous women without complicating conditions who planned birth in a non-OU setting had a significantly reduced risk of experiencing an intervention/adverse outcome requiring obstetric care (maternal composite outcome; see online supplementary tables S8 and S10). For example, $38 \%$ (95\% CI $34.3 \%$ to $41.9 \%$ ) of nulliparous 
Table 4 Relative risk for non-OU compared to OU by age groups in nulliparous women

\begin{tabular}{|c|c|c|c|}
\hline Age (years) & Unadjusted RR ${ }^{\star}(95 \% \mathrm{Cl})$ & Adjusted RR* ${ }^{\star},(95 \% \mathrm{Cl})$ & Adjusted RR ${ }^{\star}, \ddagger(95 \% \mathrm{Cl})$ \\
\hline \multicolumn{4}{|c|}{ Maternal composite } \\
\hline $16-19$ & $0.44(0.38$ to 0.53$)$ & $0.45(0.38$ to 0.54$)$ & $0.49(0.42$ to 0.58$)$ \\
\hline $20-24$ & $0.51(0.45$ to 0.57$)$ & $0.51(0.45$ to 0.58$)$ & $0.55(0.49$ to 0.62$)$ \\
\hline $25-29$ & $0.58(0.53$ to 0.64$)$ & 0.59 (0.54 to 0.65$)$ & $0.63(0.57$ to 0.70$)$ \\
\hline 30-34 & $0.60(0.55$ to 0.66$)$ & 0.61 (0.56 to 0.67$)$ & 0.66 (0.60 to 0.73$)$ \\
\hline 35-39 & 0.61 (0.54 to 0.68$)$ & $0.62(0.56$ to 0.69$)$ & 0.68 (0.61 to 0.76$)$ \\
\hline $40+$ & 0.62 (0.49 to 0.80$)$ & $0.66(0.51$ to 0.87$)$ & $0.70(0.53$ to 0.93$)$ \\
\hline \multicolumn{4}{|l|}{ Augmentation } \\
\hline $16-19$ & $0.33(0.26$ to 0.42$)$ & $0.34(0.27$ to 0.44$)$ & $0.37(0.29$ to 0.47$)$ \\
\hline $20-24$ & $0.42(0.35$ to 0.51$)$ & $0.43(0.35$ to 0.52$)$ & $0.47(0.39$ to 0.57$)$ \\
\hline $25-29$ & $0.49(0.43$ to 0.55$)$ & $0.50(0.45$ to 0.57$)$ & 0.56 (0.49 to 0.63$)$ \\
\hline 30-34 & $0.53(0.47$ to 0.60$)$ & 0.55 (0.48 to 0.63$)$ & 0.61 (0.53 to 0.71$)$ \\
\hline $35-39$ & $0.54(0.44$ to 0.65$)$ & $0.54(0.46$ to 0.64$)$ & 0.61 (0.51 to 0.74$)$ \\
\hline $40+$ & 0.50 (0.32 to 0.78$)$ & $0.53(0.33$ to 0.84$)$ & $0.58(0.36$ to 0.94$)$ \\
\hline \multicolumn{4}{|c|}{$\begin{array}{l}\text { *Probability weights are incorporated to account for differences in the probability of a woman being selected for inclusion in the study arising } \\
\text { from differences in each unit/trust's period of participation and the stratum-specific probabilities of selection of OUs. } \\
\text { †Adjusted for ethnic group, understanding of English, marital/partner status, BMI in pregnancy, index of multiple deprivation score quintile and } \\
\text { gestation at delivery. } \\
\text { fAdjusted for ethnic group, understanding of English, marital/partner status, BMI in pregnancy, index of multiple deprivation score quintile, } \\
\text { gestation at delivery and complicating conditions identified at the start of care in labour. } \\
\text { BMI, body mass index; OU, obstetric unit. }\end{array}$} \\
\hline
\end{tabular}

women aged 35-39 without complicating complications who planned birth in a non-OU setting experienced an intervention/adverse outcome requiring obstetric care, compared with $57.7 \%$ (95\% CI $53.4 \%$ to $62.0 \%)$ of women of the same age without complicating conditions who planned birth in an OU.

The use of epidural/spinal analgesia increased significantly with maternal age and lower rates of use were observed in planned non-OU births (see online supplementary figure S2). Adjustment for use of epidural in the multivariable models attenuated but did not change the results materially (data not shown).

\section{Perinatal outcome}

The perinatal composite outcome (admission to a neonatal unit within $48 \mathrm{~h}$ of birth, stillbirth after the onset of labour or early neonatal death) showed a modest but not statistically significant increase with age in nulliparous women in the age range 16-40 (table 2). The risk increased significantly in nulliparous women aged $40+$ compared with women aged 25-29 (RR 2.29, 95\% CI 1.28 to 4.09, adjusted for maternal characteristics and PPOB, all settings combined). Maternal age was not significantly associated with the risk of the perinatal composite outcome in multiparous women in the age range 16-40 (table 2) and the risk was not significantly increased in births to multiparous women aged $40+$ compared with women aged 25-29 (RR 1.21, 95\% CI 0.60 to 2.43, adjustment as before). Absolute event rates are shown in table 6 .

\section{DISCUSSION}

\section{Principal findings}

In women without known medical or obstetric risk factors prior to the onset of labour, interventions and adverse maternal outcomes requiring obstetric care generally increased with age, but there was no age at which there was a step-change in risk. For nulliparous and multiparous women, maternal intervention rates were lower in births planned in non-OU settings compared with planned OU births at all ages. For nulliparous women, the overall risk of experiencing an intervention or adverse outcome requiring obstetric care, and in particular of augmentation with syntocinon, increased more steeply with age in planned non-OU births than in planned OU births. As a consequence, although nulliparous women of all ages who planned birth in a non-OU setting had a significantly reduced risk of experiencing an intervention or adverse outcome requiring obstetric care, the benefit of planned non-OU birth was greatest at younger ages.

In low-risk women up to the age of 40, the risk of neonatal unit admission or intrapartum stillbirth/early neonatal death did not show a statistically significant upward trend with age in either nulliparous or multiparous women. In planned OU births, the risk of neonatal unit admission or perinatal death was significantly higher in nulliparous women aged $40+$ relative to women aged 25-29.

\section{Strengths and limitations}

A strength of the study is that we were able to evaluate the effect of age on intrapartum outcomes by planned birth setting in a nationally representative sample of 'low-risk' women. In order to strengthen the evidence supporting clinical guidelines on PPOB, the study specifically focused on outcomes that reflect the need for obstetric or neonatal care in a sample of women who meet the current criteria for planned birth in a non-OU setting. ${ }^{22}$ To our knowledge, this is the first study to 
Table 5 Intrapartum interventions and adverse maternal outcomes by maternal age in low-risk multiparous women aged 16 and over

\begin{tabular}{|c|c|c|c|c|c|c|}
\hline \multirow[b]{3}{*}{ Age (years) } & \multirow{3}{*}{$\begin{array}{l}\text { Events/births } \\
\mathrm{n} / \mathrm{N}\end{array}$} & \multicolumn{2}{|l|}{ OU } & \multirow{3}{*}{$\begin{array}{l}\text { Events/births } \\
\mathrm{n} / \mathrm{N}\end{array}$} & \multirow{2}{*}{\multicolumn{2}{|c|}{$\frac{\text { Non-OU }}{\text { Weighted }^{\star}}$}} \\
\hline & & \multicolumn{2}{|c|}{ Weighted $^{*}$} & & & \\
\hline & & $\%$ & $(95 \% \mathrm{Cl})$ & & $\%$ & $(95 \% \mathrm{Cl})$ \\
\hline \multicolumn{7}{|c|}{ Maternal composite } \\
\hline $16-19$ & $35 / 177$ & 20.2 & (14.1 to 28.0 ) & $20 / 338$ & 6.6 & (4.1 to 10.6$)$ \\
\hline $20-24$ & $242 / 1506$ & 16.2 & (13.8 to 19.0$)$ & $146 / 3486$ & 4.6 & (3.6 to 5.8 ) \\
\hline $25-29$ & $468 / 2504$ & 18.9 & (16.9 to 20.9 ) & 297/6989 & 4.8 & (4.1 to 5.7$)$ \\
\hline $30-34$ & $492 / 2548$ & 19.2 & (16.8 to 21.8 ) & $418 / 8440$ & 5.4 & (4.7 to 6.2 ) \\
\hline 35-39 & $344 / 1575$ & 21.9 & (19.4 to 24.7 ) & $273 / 5737$ & 5.6 & (4.8 to 6.6$)$ \\
\hline $40+$ & $82 / 340$ & 24.1 & (20.7 to 28.0 ) & $65 / 975$ & 7.4 & (5.6 to 9.7 ) \\
\hline Total & $1663 / 8650$ & 19.3 & (17.6 to 21.1 ) & $1219 / 25965$ & 5.3 & (4.7 to 5.9$)$ \\
\hline \multicolumn{7}{|l|}{ Augmentation } \\
\hline $16-19$ & $19 / 178$ & 10.5 & (5.9 to 17.9 ) & $11 / 340$ & 3.8 & (2.0 to 7.1$)$ \\
\hline $20-24$ & $144 / 1516$ & 9.4 & (7.5 to 11.8$)$ & $62 / 3520$ & 2.0 & (1.4 to 2.7$)$ \\
\hline $25-29$ & $247 / 2529$ & 9.9 & (8.2 to 12.0$)$ & $109 / 7077$ & 1.8 & (1.4 to 2.3 ) \\
\hline 30-34 & $255 / 2572$ & 9.7 & (8.0 to 11.7$)$ & $132 / 8535$ & 1.6 & (1.3 to 2.0$)$ \\
\hline 35-39 & $156 / 1592$ & 9.8 & (8.2 to 11.6$)$ & $89 / 5796$ & 1.8 & (1.3 to 2.5$)$ \\
\hline $40+$ & $42 / 345$ & 12.2 & (9.5 to 15.5$)$ & $18 / 985$ & 1.8 & (1.1 to 3.2$)$ \\
\hline Total & $863 / 8732$ & 9.8 & (8.5 to 11.4$)$ & $421 / 26253$ & 1.8 & (1.5 to 2.1$)$ \\
\hline \multicolumn{7}{|c|}{ Instrumental delivery } \\
\hline $16-19$ & $12 / 179$ & 7.5 & (3.6 to 14.9 ) & $7 / 340$ & 3.1 & (1.3 to 7.1$)$ \\
\hline $20-24$ & $55 / 1530$ & 3.6 & (2.7 to 4.9$)$ & $38 / 3520$ & 1.4 & (1.0 to 2.0$)$ \\
\hline $25-29$ & $139 / 2557$ & 5.5 & (4.6 to 6.5$)$ & $102 / 7092$ & 1.8 & (1.4 to 2.3$)$ \\
\hline $30-34$ & $159 / 2594$ & 6.1 & (5.0 to 7.5$)$ & $124 / 8544$ & 1.6 & (1.2 to 2.0$)$ \\
\hline 35-39 & $102 / 1600$ & 6.6 & (5.0 to 8.6$)$ & $82 / 5802$ & 1.8 & (1.4 to 2.4$)$ \\
\hline $40+$ & $30 / 347$ & 8.8 & (5.5 to 13.8$)$ & $17 / 987$ & 2.5 & (1.3 to 4.7$)$ \\
\hline Total & $497 / 8807$ & 5.7 & (4.9 to 6.7$)$ & $370 / 26285$ & 1.7 & (1.4 to 2.1$)$ \\
\hline \multicolumn{7}{|c|}{ Intrapartum caesarean section } \\
\hline $16-19$ & $6 / 179$ & 3.4 & (1.4 to 7.7$)$ & $4 / 340$ & 0.9 & (0.3 to 2.5$)$ \\
\hline $20-24$ & $62 / 1530$ & 4.1 & (2.6 to 6.3$)$ & $21 / 3520$ & 0.6 & (0.3 to 1.1$)$ \\
\hline $25-29$ & $121 / 2557$ & 4.8 & (3.8 to 6.1$)$ & 48/7092 & 0.7 & (0.5 to 0.9$)$ \\
\hline 30-34 & $134 / 2594$ & 5.1 & (4.0 to 6.5$)$ & $70 / 8544$ & 0.9 & (0.6 to 1.2$)$ \\
\hline 35-39 & $110 / 1600$ & 6.8 & (5.1 to 9.1$)$ & $53 / 5802$ & 1.1 & (0.8 to 1.5$)$ \\
\hline $40+$ & $16 / 347$ & 4.8 & (3.1 to 7.4$)$ & $15 / 987$ & 1.5 & (0.8 to 2.7$)$ \\
\hline Total & $449 / 8807$ & 5.1 & (4.2 to 6.3 ) & $211 / 26285$ & 0.8 & (0.7 to 1.1$)$ \\
\hline
\end{tabular}

*Percentages are weighted to take account of differences in the probability of a woman being selected for inclusion in the study arising from differences in each unit/trust's period of participation and the stratum-specific probabilities of selection of OUs.

OU, obstetric unit.

investigate the effect of increasing maternal age in different birth settings with a focus on outcomes that would require transfer to an $\mathrm{OU}$ and hence may affect the choice of PPOB.

Despite the large overall sample size, the number of older women was relatively small, so we had a limited ability to explore the effects above age 40 or to separate the results for individual non-OU birth settings. We combined data for the non-OU settings, having first explored the data to check that this was reasonable. This increased our statistical power to evaluate the association between maternal age and the study outcomes (maternal and perinatal), but we still lacked the statistical power to evaluate uncommon outcomes. It is important to note that previous analyse ${ }^{25}$ have shown that planned home births are associated with a significantly increased risk of adverse perinatal outcomes in nulliparous women.
The risk of bias due to missing data and non-response was low; the study had a low level of missing data, a high response rate $e^{2526}$ and, because consent was not required, there was no self-selection bias due to non-consent. We addressed potential differences in risk between groups in a number of ways. First, we controlled for important potential confounders such as BMI. Second, we focused on a relatively homogeneous population of women without known medical or obstetric risk factors prior to the onset of labour. Third, because previous analyse ${ }^{25}$ identified that the prevalence of complicating conditions at the start of care in labour was higher in the planned OU birth group, we conducted two additional analyses in which we controlled for complicating conditions and restricted the analysis to women without complicating conditions. Differences in the clinical characteristics of the OU and non-OU groups therefore seem unlikely to explain the age-related trends observed or the significant 
Table 6 Perinatal outcomes by maternal age in low-risk women aged 16 and over

\begin{tabular}{|c|c|c|c|c|c|c|}
\hline \multirow[b]{3}{*}{ Age (years) } & \multirow{3}{*}{$\begin{array}{l}\text { Events/births } \\
\mathrm{n} / \mathrm{N}\end{array}$} & \multirow{2}{*}{\multicolumn{2}{|c|}{$\frac{\text { OU }}{\text { Weighted }^{\star}}$}} & \multirow{3}{*}{$\begin{array}{l}\text { Events/births } \\
\mathrm{n} / \mathrm{N}\end{array}$} & \multirow{2}{*}{\multicolumn{2}{|c|}{$\frac{\text { Non-OU }}{\text { Weighted }^{\star}}$}} \\
\hline & & & & & & \\
\hline & & $\%$ & $(95 \% \mathrm{Cl})$ & & $\%$ & (95\% Cl) \\
\hline \multicolumn{7}{|l|}{ Nulliparous } \\
\hline $16-19$ & $39 / 1260$ & 3.2 & (2.2 to 4.5 ) & $31 / 1553$ & 2.9 & (1.9 to 4.4$)$ \\
\hline 20-24 & $89 / 2610$ & 3.5 & (2.5 to 5.0$)$ & $94 / 3700$ & 2.4 & (1.9 to 3.2 ) \\
\hline $25-29$ & $92 / 3026$ & 3.3 & (2.6 to 4.0$)$ & $123 / 5357$ & 2.1 & (1.7 to 2.8$)$ \\
\hline $30-34$ & $101 / 2340$ & 4.2 & (3.1 to 5.6 ) & $128 / 4918$ & 3.0 & (2.2 to 4.0$)$ \\
\hline 35-39 & $37 / 962$ & 3.9 & (2.8 to 5.4 ) & $65 / 1999$ & 3.0 & (2.1 to 4.1 ) \\
\hline $40+$ & $10 / 149$ & 7.5 & (3.4 to 15.7 ) & $8 / 195$ & 3.9 & (1.0 to 14.0$)$ \\
\hline Total & $368 / 10347$ & 3.7 & (2.9 to 4.6$)$ & 449/17 722 & 2.6 & (2.2 to 3.1$)$ \\
\hline \multicolumn{7}{|l|}{ Multiparous } \\
\hline $16-19$ & $6 / 179$ & 3.0 & (1.4 to 6.4$)$ & $5 / 337$ & 1.7 & (0.6 to 4.6$)$ \\
\hline $20-24$ & $26 / 1519$ & 1.8 & (1.2 to 2.7 ) & 43/3489 & 1.3 & (0.8 to 2.0 ) \\
\hline $25-29$ & $41 / 2547$ & 1.6 & (1.2 to 2.3$)$ & 73/7032 & 1.1 & (0.8 to 1.6$)$ \\
\hline $30-34$ & $50 / 2578$ & 2.0 & (1.5 to 2.6$)$ & $111 / 8468$ & 1.2 & (1.0 to 1.5$)$ \\
\hline $35-39$ & $33 / 1594$ & 2.1 & (1.3 to 3.3$)$ & $88 / 5761$ & 1.6 & (1.2 to 2.2 ) \\
\hline $40+$ & $7 / 345$ & 2.1 & (0.9 to 4.6$)$ & $20 / 978$ & 2.3 & (1.3 to 4.1$)$ \\
\hline Total & $163 / 8762$ & 1.9 & (1.5 to 2.4 ) & $340 / 26065$ & 1.3 & (1.1 to 1.6$)$ \\
\hline
\end{tabular}

*Percentages are weighted to take account of differences in the probability of a woman being selected for inclusion in the study arising from differences in each unit/trust's period of participation and the stratum-specific probabilities of selection of OUs.

OU, obstetric unit.

reductions in risks observed in non-OU births. Nevertheless, women self-select their birth setting and it may be that some of the differences in the outcomes that we observed between settings may have been due to unmeasured differences in the characteristics of women opting for OU and non-OU births, rather than to differences attributable to the birth setting.

\section{Comparison with the existing literature}

Older women have been shown to have an increased risk of intrapartum intervention, ${ }^{6}{ }^{32}$ but many studies include women known to be at higher risk who would normally be advised to give birth in an OU. Evidence relating to 'low-risk' women ${ }^{17}$ or from studies that have controlled for pre-existing risk factors or complications ${ }^{33}$ is more limited but is generally consistent with our finding that intervention rates increase with age in 'low-risk' women.

There is extensive evidence that 'low-risk' women who plan birth in a non-OU setting have a reduced risk of a range of intrapartum interventions, including augmentation, instrumental delivery and intrapartum caesarean section, and are more likely to have a spontaneous vaginal birth. ${ }^{22-24} 2728$ Our study found that, at all ages, women who plan birth in a non-OU setting experience substantially lower intervention rates and are less likely to experience an outcome requiring obstetric care than women of the same age who plan birth in an OU.

In nulliparous women, we found that the rates of augmentation of labour with syntocinon increased more steeply with maternal age in planned non-OU births compared with planned OU births, although absolute rates of augmentation were substantially lower in planned non-OU births at all ages. An age-related increase in augmentation is consistent with evidence of poorer uterine function at older ages, ${ }^{34}$ longer labours ${ }^{34}$ and an increased incidence of prolonged labour, ${ }^{35} 36$ but the reasons for a steeper increase in augmentation with age in non-OU settings are unclear. It has been suggested that labelling of older women as 'higher risk' and/or heightened concern about the safety of older nulliparous women, particularly those who have required fertility treatment, may result in increased rates of caesarean section for non-medical reasons, ${ }^{20} 32 \quad 33 \quad 37$ and it is possible that similar factors affect midwives' decision-making regarding transfer for failure to progress, or for other reasons. Intrapartum transfers from midwifery units in the Birthplace study have been shown to increase significantly with age in nulliparous women ${ }^{29}$ and, once transferred, women are 'exposed' to the higher intervention rates found in OUs.

It is also possible that age-related differences in women's expectations and expressed preferences may contribute to the pattern of intervention observed in our study. Older nulliparous women have been found to have a more positive attitude towards caesarean section, ${ }^{38}$ and also have a higher perception of pregnancy risk, even in older women without known risk factors. ${ }^{39}$ The significant positive association between maternal age and epidural use observed in our study (seen most strongly in nulliparous women planning a non-OU birth) would be consistent with a greater willingness of older women to consider interventions.

We found a significantly increased risk of maternal admission for higher level care at older ages in nulliparous and multiparous women. The number of events was small 
and this could be a chance finding but an increase in serious obstetric complications at older ages observed in some studies ${ }^{3612}$ cannot be ruled out.

Although studies including women with known risk factors have reported increased risks in women aged over $35,{ }^{3635}$ our analysis shows that up to the age of 40 , risks tend to increase in a broadly linear manner in healthy women with straightforward pregnancies, with no evidence of a step-change in risk below the age of 40 . Other studies have similarly concluded that the association of adverse outcomes with maternal age is a continuum, ${ }^{3}$ with the increase in adverse perinatal outcomes possibly gaining momentum above the age of $40 .{ }^{40}$ Owing to the small number of births to mothers aged over 40 in our sample, we had limited power to evaluate the risks at older ages, and other evidence relating to older 'low-risk' women is sparse. ${ }^{21}$

There is some evidence that the babies of older women are at an increased risk of serious adverse outcomes, including intrapartum-related perinatal death, ${ }^{14}$ early neonatal death ${ }^{15}$ and neonatal unit admission, ${ }^{5} 33$ but these outcomes would be expected to be substantially reduced in 'low-risk' women who, by definition, do not have medical or obstetric risk factors such as severe obesity, diabetes or previous caesarean section. Furthermore, the poorer outcomes associated with the increased risk of pre-term birth at older ages do not apply to women giving birth at term. In our 'low-risk' cohort, we did not observe a significant increase with age in our composite measure of neonatal unit admission/perinatal death within the age range 16-40, but graphical plots for nulliparous women suggested a possible upturn in neonatal unit admission/perinatal death around the age of 40 in nulliparous women. Further research evaluating perinatal outcomes in 'low-risk' women aged over 40 is needed.

\section{CONCLUSIONS AND POLICY IMIPLICATIONS}

The incidence of intrapartum interventions and adverse outcomes requiring obstetric care increases with maternal age, but at all ages 'low-risk' women who plan birth in a non-OU setting tend to experience lower intervention rates than comparable women who plan birth in an OU. Among nulliparous women, younger women appear to benefit more from the reduction in interventions associated with planned birth in a non-OU setting. Increased intervention rates at older ages may partly reflect women's expectations and preferences and possibly 'higher risk' labelling by clinicians.

All women, irrespective of age and parity, should be given information about the risks and benefits of different birth settings. Nulliparous women planning birth in non-OU settings should be informed that the risk of interventions that require transfer to an $\mathrm{OU}$ increases with age. Further research is required to evaluate the adverse perinatal outcomes in 'low-risk' women aged over 40 .
Author affiliations

${ }^{1}$ Policy Research Unit in Maternal Health and Care, National Perinatal Epidemiology Unit, Nuffield Department of Population Health, University of Oxford, Oxford, UK

${ }^{2}$ Institute for Women's Health, University College London, London, UK

Acknowledgements The authors would like to thank Xiaosi Wang for conducting initial literature searches and statistical analysis.

Contributors $\mathrm{JH}$ conceived and developed the study outline with input from $\mathrm{PB}$; YL developed the protocol and analysis plan with input from JH, JT and MK; YL conducted the analysis; JT provided statistical advice; YL and JH drafted the manuscript with input from RR, MK and PB. All authors were involved in interpretation of data, review and revision of the draft manuscript and approval of the final version.

Funding This paper reports on an independent study which is funded by the Policy Research Programme in the Department of Health (Award 108/0001). The views expressed are not necessarily those of the Department. Birthplace combines the Evaluation of Maternity Units in England study funded in 2006 by the National Institute for Health Research Service Delivery and Organisation (NIHR SDO) programme, and the Birth at Home in England study funded in 2007 by the Department of Health Policy Research Programme (DH PRP).

The views and opinions expressed by the authors do not necessarily reflect those of the HS\&DR Programme, NIHR, NHS, DH PRP or the Department of Health.

\section{Competing interests None.}

Ethics approval Research ethics committee approval for the Birthplace study was obtained from the Berkshire Research Ethics Committee (MREC ref 07/ H0505/151)

Provenance and peer review Not commissioned; externally peer reviewed.

Data sharing statement No additional data are available.

Open Access This is an Open Access article distributed in accordance with the Creative Commons Attribution Non Commercial (CC BY-NC 3.0) license, which permits others to distribute, remix, adapt, build upon this work noncommercially, and license their derivative works on different terms, provided the original work is properly cited and the use is non-commercial. See: http:// creativecommons.org/licenses/by-nc/3.0/

\section{REFERENCES}

1. Office for National Statistics. Live births in England and Wales by characteristics of mother 1, 2011. November 2013. http://www.ons. gov.uk/ons/dcp171778 296157.pdf

2. Martin JA, Hamilton BE, Ventura SJ, et al. Births: final data for 2009. Natl Vital Stat Rep 2011;60:1-70.

3. Biro MA, Davey M-A, Carolan M, et al. Advanced maternal age and obstetric morbidity for women giving birth in Victoria, Australia: a population-based study. Aust N Z J Obstet Gynaecol 2012;52:229-34.

4. Carolan $M$. Maternal age $\geq 45$ years and maternal and perinatal outcomes: a review of the evidence. Midwifery 2013;29:479-89.

5. Delbaere I, Verstraelen H, Goetgeluk S, et al. Pregnancy outcome in primiparae of advanced maternal age. Eur J Obstetr Gynecol Reprod Biol 2007;135:41-6.

6. Jolly M, Sebire N, Harris J, et al. The risks associated with pregnancy in women aged 35 years or older. Hum Reprod 2000;15:2433-7.

7. Ananth CV, Demissie K, Smulian JC, et al. Placenta previa in singleton and twin births in the United States, 1989 through 1998: a comparison of risk factor profiles and associated conditions. Am J Obstet Gynecol 2003;188:275-81.

8. Ananth CV, Wilcox AJ, Savitz DA, et al. Effect of maternal age and parity on the risk of uteroplacental bleeding disorders in pregnancy. Obstet Gynecol 1996;88(4, Pt 1):511-16.

9. Faiz AS, Ananth CV. Etiology and risk factors for placenta previa: an overview and meta-analysis of observational studies. J Matern Fetal Neonatal Med 2003;13:175-90.

10. Jacobsson B, Ladfors L, Milsom I. Advanced maternal age and adverse perinatal outcome. Obstet Gynecol 2004;104:727-33. 
11. Roos N, Sahlin L, Ekman-Ordeberg G, et al. Maternal risk factors for postterm pregnancy and cesarean delivery following labor induction. Acta Obstet Gynecol Scand 2010;89:1003-10.

12. Knight $\mathrm{M}$, Kurinczuk JJ, Spark $\mathrm{P}$, et al. Inequalities in maternal health: national cohort study of ethnic variation in severe maternal morbidities. BMJ 2009;338:b542

13. Huang L, Sauve R, Birkett N, et al. Maternal age and risk of stillbirth: a systematic review. Can Med Assoc J 2008;178:165-72.

14. Pasupathy D, Wood AM, Pell JP, et al. Advanced maternal age and the risk of perinatal death due to intrapartum anoxia at term. J Epidemiol Community Health 2011;65:241-5.

15. Gilbert WM, Nesbitt TS, Danielsen B. Childbearing beyond age 40: pregnancy outcome in 24,032 cases. Obstet Gynecol 1999;93:9-14.

16. Ezra $Y$, McParland $P$, Farine $D$. High delivery intervention rates in nulliparous women over age 35. Eur J Obstetr Gynecol Reprod Biol 1995;62:203-7. http://dx.doi.org/10.1016/0301-2115(95)02201-H

17. Gordon D, Milberg J, Daling J, et al. Advanced maternal age as a risk factor for cesarean delivery. Obstet Gynecol 1991;77:493-7.

18. Heffner LJ, Elkin E, Fretts RC. Impact of labor induction, gestational age, and maternal age on cesarean delivery rates. Obstet Gynecol 2003;102:287-93

19. Patel RR, Peters TJ, Murphy DJ, et al. Prenatal risk factors for caesarean section. Analyses of the ALSPAC cohort of 12944 women in England. Int J Epidemiol 2005;34:353-67.

20. Peipert JF, Bracken MB. Maternal age: an independent risk factor for cesarean delivery. Obstet Gynecol 1993;81:200-5.

21. Carolan $\mathrm{M}$. The graying of the obstetric population: implications for the older mother. J Obstet Gynecol Neonatal Nurs 2003;32:19-27.

22. National Collaborating Centre for Women's and Children's Health. Intrapartum care of healthy women and their babies during childbirth. Commissioned by the National Institute for Health and Clinical Excellence (NICE). London: RCOG Press, 2007.

23. Hodnett ED, Downe S, Walsh D. Alternative versus conventional institutional settings for birth. Cochrane Database Syst Rev 2012;8: CD000012.

24. Walsh D, Downe SM. Outcomes of free-standing, midwife-led birth centers: a structured review. Birth 2004;31:222-9.

25. Birthplace in England Collaborative Group. Perinatal and maternal outcomes by planned place of birth for healthy women with low risk pregnancies: the Birthplace in England national prospective cohort study. BMJ 2011;343:d7400.

26. Hollowell J, Puddicombe D, Rowe R, et al. The Birthplace national prospective cohort study: perinatal and maternal outcomes by planned place of birth. Birthplace in England research programme. Final report part 4. NIHR Service Delivery and Organisation programme, 2011.
27. Lindgren HE, Radestad IJ, Christensson K, et al. Outcome of planned home births compared to hospital births in Sweden between 1992 and 2004. A population-based register study. Acta Obstet Gynecol Scand 2008:87:751-9.

28. Janssen PA, Saxell L, Page LA, et al. Outcomes of planned home birth with registered midwife versus planned hospital birth with midwife or physician. CMAJ 2009;181:377-83.

29. Rowe RE, Fitzpatrick R, Hollowell J, et al. Transfers of women planning birth in midwifery units: data from the Birthplace prospective cohort study. BJOG 2012;119:1081-90.

30. Redshaw M, Rowe R, Schroeder L, et al. Mapping maternity care. The configuration of maternity care in England. Birthplace in England research programme. Final report part 3. NIHR Service Delivery and Organisation programme, 2011

31. Fan J, Gijbels I. Local polynomial modelling and its applications. London: Chapman \& Hall, 1996.

32. Bayrampour $\mathrm{H}$, Heaman $\mathrm{M}$. Advanced maternal age and the risk of Cesarean birth: a systematic review. Birth 2010;37: 219-26.

33. Bell JS, Campbell DM, Graham WJ, et al. Can obstetric complications explain the high levels of obstetric interventions and maternity service use among older women? A retrospective analysis of routinely collected data. BJOG 2001;108:910-18.

34. Main DM, Main EK, Moore li DH. The relationship between maternal age and uterine dysfunction: a continuous effect throughout reproductive life. Am J Obstet Gynecol 2000;182: 1312-20.

35. Berkowitz GS, Skovron ML, Lapinski RH, et al. Delayed childbearing and the outcome of pregnancy. $N$ Engl J Med 1990;322:659-64.

36. Greenberg MB, Cheng YW, Sullivan M, et al. Does length of labor vary by maternal age? Am J Obstet Gynecol 2007;197:428. e1-e7.

37. Cnattingius R, Cnattingius S, Notzon FC. Obstacles to reducing cesarean rates in a low-cesarean setting: the effect of maternal age, height, and weight. Obstet Gynecol 1998;92(4, Pt 1):501-6.

38. Aasheim V, Waldenstrom $\mathrm{U}$, Rasmussen $\mathrm{S}$, et al. Experience of childbirth in first-time mothers of advanced age-a Norwegian population-based study. BMC Pregnancy Childbirth 2013;13:53.

39. Bayrampour H, Heaman M, Duncan KA, et al. Comparison of perception of pregnancy risk of nulliparous women of advanced maternal age and younger age. J Midwifery Women's Health 2012;57:445-53.

40. Carolan M, Frankowska D. Advanced maternal age and adverse perinatal outcome: a review of the evidence. Midwifery 2011;27:793-801. 